\title{
SOME FACTS RESULTING FROM THE KEY VARIABLES USED IN THE DESCRIPTION OF THE RECUPERATIVE HEAT EXCHANGERS
}

\author{
GUŽELA Štefan ${ }^{1 \mathrm{a}}$, DZIANIK František ${ }^{1 \mathrm{~b}}$ \\ ${ }^{1}$ Slovak University of Technology in Bratislava, Faculty of Mechanical Engineering, Nám. slobody 17, 81231 \\ Bratislava 1, Slovak Republic,e-mail: astefan.guzela@stuba.sk, bfrantisek.dzianik@ stuba.sk
}

\begin{abstract}
There are the various types of heat exchangers. The selection of the heat exchanger right type is the first basic assumption for its optimal operation. The heat exchanger calculation itself is another prerequisite for its optimal operation. This article deals with the variables which are usually used to describe the stationary operation of any recuperative heat exchanger with two incoming and two outgoing streams. The knowledge of these variables, including the facts resulting from them, is necessary not only from the point of view of the calculation but also from the point of view of the evaluation of the experimental data of any heat exchanger. The variables values needed for the calculation of heat exchangers, so-called key variables, must always fall within the values range determined on the basis of generally valid knowledge about heat exchangers. The article also deals with the determination of the limit values defining the values range of these key variables.
\end{abstract}

KEYWORDS: Heat exchanger, recuperative heat exchanger, heat exchanger efficiency, number of transfer units, NTU, countercurrent index.

\section{$1 \quad$ Introduction}

The heat exchangers are an indispensable part not only of many industrial plants but they are also part of the various devices $[1,2,3,4,5]$. The heat exchangers calculation can be done in different ways. Several computational methods have developed over time. The methods which work with the dimensionless quantities have found the greatest justification. Method LMTD [6], Method $\varepsilon-N T U$ [7], Method $\theta-N T U$ [8] belong among the most important. These methods define some variables, for example: $F, \theta$ and $\mathrm{NTU}_{\min }$, which knowledge is very important for solving any heat exchanger. These variables have been introduced due to the fact that some types of heat exchangers cannot be even at present described by any exact relationships. The variables $F, \theta$ and $\mathrm{NTU}_{\text {min }}$, so-called key variables, are determined on the basis of experimental measurements. The equations that define these variables can be written in the form $[2,9,10]$ :

$$
\begin{gathered}
F=\overline{\Delta T} / \Delta T_{\mathrm{ln}}=\overline{\Delta T} / L M T D=\overline{\Delta T} \frac{\ln \left[\left(T_{h}^{\prime}-T_{c}^{\prime \prime}\right) /\left(T_{h}^{\prime \prime}-T_{c}^{\prime}\right)\right]}{\left[\left(T_{h}^{\prime}-T_{c}^{\prime \prime}\right)-\left(T_{h}^{\prime \prime}-T_{c}^{\prime}\right)\right]}, \\
\theta=\overline{\Delta T} /\left(T_{h}^{\prime}-T_{c}^{\prime}\right), \\
\mathrm{NTU}_{\text {min }}=\bar{k} A / \bar{C}_{p \text { min }} .
\end{gathered}
$$

In the equation (3), the index min represents one of two streams, so-called weak stream, which $\bar{C}_{p i}=\dot{m}_{i} \bar{c}_{p i}$ is smaller (i.e. $\bar{C}_{p \text { min }}=\min \left\{\bar{C}_{p h} ; \bar{C}_{p c}\right\}$ ). The second stream, so-called stronger stream, is denoted by the index max. Variables $F, \theta$ and $N T U_{\text {min }}$ are a clearly 
function of variables $P_{i}$ and $R_{i}$. These variables are defined by the following equations [2, 9, 10]:

$$
\begin{gathered}
P_{h}=\left(T_{h}^{\prime}-T_{h}^{\prime \prime}\right) /\left(T_{h}^{\prime}-T_{c}^{\prime}\right) \text { a } P_{c}=\left(T_{c}^{\prime \prime}-T_{c}^{\prime}\right) /\left(T_{h}^{\prime}-T_{c}^{\prime}\right), \\
R_{c}=\bar{C}_{p c} / \bar{C}_{p h}=\left(T_{h}^{\prime}-T_{h}^{\prime \prime}\right) /\left(T_{c}^{\prime \prime}-T_{c}^{\prime}\right)=1 / R_{h} .
\end{gathered}
$$

The stationary operation of a heat exchanger is typically described by the functions:

$$
\mathrm{f}\left(P_{i}, R_{i}, F\right)=0, \mathrm{f}\left(P_{i}, R_{i}, \mathrm{NTU}_{i}\right)=0 \text { or: } \mathrm{f}\left(P_{i}, R_{i}, \theta\right)=0 .
$$

These functions are general and result from the above. The various dependencies, analytical or graphical, describing the heat exchanger behavior are compiled just on the basis of the equation (6). Some of these dependencies, which knowledge is significant for calculation any heat exchanger, are listed in literature [10, 11, 12].

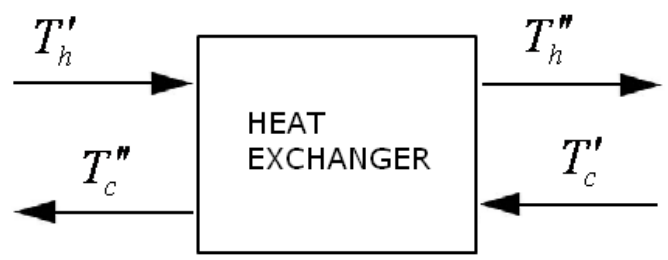

Fig. 1 Schematic representation of the heat exchanger streams.

In literature $[9,10]$, variables corresponding to the weaker stream are also indicated by the lower index 1 instead of the index min (i.e. $P_{1}=P_{\text {min }}, R_{1}=R_{\min }$ a $\mathrm{NTU}_{1}=\mathrm{NTU}_{\min }$ ). The stronger stream is similarly indicated by the lower index 2 . The variable $P_{1}$ is identical with the variable $\Phi$, so-called heat exchanger efficiency, if the lower index 1 indicates the weak stream (i.e. $\left.P_{1}=P_{\min }=\Phi\right)[9,13]$. This follows from the equation which defines the heat exchanger efficiency $(\Phi)$. The shape of this equation is following:

$$
\Phi=\dot{Q} / \dot{Q}_{\max }=\bar{C}_{p h} P_{h} / \bar{C}_{p \min }=\bar{C}_{p c} P_{c} / \bar{C}_{p \min } .
$$

The value of the variable $P_{\min }=P_{1}$, but also $P_{\max }=P_{2}$, is always from the interval of the values from 0 to 1 , including 0 and 1 (i.e. $P_{i} \in\langle 0 ; 1\rangle$ ). This does not apply in the case of the variable $R_{i}$ which is determined according to the equation (5). The value of this variable is in the range: $0 \leq R_{i} \leq \infty$, but the value of $R_{1}=R_{\min }$ is always in the range from 0 to 1 (i.e. $\left.R_{1}=R_{\text {min }} \in\langle 0 ; 1\rangle\right)$. In the next text, the variables pertaining to the weaker stream will be denoted by the lower index 1 .

It should be mentioned that each heat exchanger is characterised by different construction (different flow arrangement). Therefore, the different values of the variables (for example: $C_{p i}, A, T_{i}$ ) can generally be obtained if the calculations of the heat exchangers with the different flow arrangements are made for the same input parameters. It can be stated on the basis of the just mentioned that a functional dependency (for example in the form: $F=\mathrm{f}\left(P_{1}, R_{1}\right), P_{1}=\mathrm{f}\left(\mathrm{NTU}_{1}, R_{1}\right)$ or $\left.\theta=\mathrm{f}\left(P_{1}, R_{1}\right)\right)$ is to be determined separately for each heat exchanger. The heat exchanger exact calculation cannot be made if the functional dependency (6) is not known. In some cases, such dependencies may be narrow-profile goods, or these are not at all available in the case of a preliminary calculation of the new heat exchanger type. In such cases, it is necessary to build on the current knowledge about the heat exchangers. The purpose of this article is also to show how one of the key variables (i.e. $F, \mathrm{NTU}_{1}$ or $\theta$ ) can 
be determined so that an adequate calculation of the heat exchanger can be made in certain cases.

\section{Universal equations used to describe the recuperative heat exchangers}

There is an exact analytical dependency, valid for any recuperative heat exchanger, which connects all key variables used in the description of these equipment's. The shape of this general dependency is the following [9]:

$$
\theta=\frac{P_{1}}{\mathrm{NTU}_{1}}=\frac{F\left(1-R_{1}\right) P_{1}}{\ln \left(\left(1-P_{1} R_{1}\right) /\left(1-P_{1}\right)\right)}, \text { or: } P_{1}=\frac{1-\mathrm{e}^{F\left(1-R_{1}\right) \mathrm{NTU}_{1}}}{R_{1}-\mathrm{e}^{F\left(1-R_{1}\right) \mathrm{NTU}_{1}}} .
$$

The disadvantage of this dependency from the point of view of the heat exchanger calculation is that it contains two unknown key variables. It means that the equation (8) allows to carry out only the verification of the calculated values.

The equation (8) can only be used for a pure countercurrent heat exchanger which is characterised by the following fact: $F$ is always equal to 1 for any combination of values $P_{1}$ and $R_{1}$. In other cases, $F$ is always from the value range 0 to 1 , including 0 and 1 (i.e. $F \in\langle 0 ; 1\rangle)$. The value of the variable $\theta$ is also from the same interval of values (i.e. $\theta \in\langle 0 ; 1\rangle$ ). In the case of the pure countercurrent heat exchanger, the key variables $\mathrm{NTU}_{1}$ and $\theta$ can be determined by the equations:

$$
\mathrm{NTU}_{1}=\frac{\ln \left(\left(1-P_{1} R_{1}\right) /\left(1-P_{1}\right)\right)}{\left(1-R_{1}\right)}=\mathrm{NTU}_{1 C}, \text { or: } \theta=\frac{\left(1-R_{1}\right) P_{1}}{\ln \left(\left(1-P_{1} R_{1}\right) /\left(1-P_{1}\right)\right)}=\theta_{C},
$$

resulting from the equation (8). The following equation may be also written:

$$
F=\mathrm{NTU}_{1 C} / \mathrm{NTU}_{1}=\left(P_{1} / \mathrm{NTU}_{1}\right) /\left(P_{1} / \mathrm{NTU}_{1 C}\right)=\theta / \theta_{C} .
$$

This equation, which is a combination of equations (8) and (9), is also general and is valid for any heat exchanger. The equation (10) says that the variables $\mathrm{NTU}_{1 C}$ and $\theta_{C}$ belong to any heat exchanger. The meaning of this equation is such that by means of it can obtain the values of variables $\mathrm{NTU}_{1 C}$ and $\theta_{C}$ independently of the equation (9). The reason is that the heat exchangers calculation methods work with the functional dependencies which are independent of the equation (8). It means that two independent equations, equation (9) and (10), are available for determination of $\mathrm{NTU}_{1 C}$ and $\theta_{C}$. The same values of variables $\mathrm{NTU}_{1 C}$ or $\theta_{C}$ have to be obtained from both equations if the heat exchanger calculation is done correctly. In other cases, the heat exchanger is either over-dimensioned or under-dimensioned. The heat exchanger is over-dimensioned if $\mathrm{NTU}_{1 C}$ determined by the equation (10) is larger than the value according to the equation (9). Otherwise, it is under-dimensioned. The accuracy of the calculation can also be characterised by $\theta_{C}$. The heat exchanger is overdimensioned if $\theta_{C}$ determined by the equation (10) is lower than the value according to the equation (9). Otherwise, it is under-dimensioned.

Consider the following example in which it was found that $F=0.983$ and $\mathrm{NTU}_{1}=0.840$ for the heat exchanger with parameters $P_{1}=0.535$ and $R_{1}=0.111$. If the relevant data put into the equation (8) so $P_{1}=0.549$. It means that the parameters belonging to this heat exchanger do not comply with the general equation (i.e. with the equation (8)). The heat 
exchanger is either over-dimensioned or under-dimensioned. If the data put into equations (9) and (10), according to the equation (9) $\mathrm{NTU}_{1 C}=0.792$ and $\theta_{C}=0.675$ and according to the equation (10) $\mathrm{NTU}_{1 C}=0.840 * 0.983=0.826$ and $\theta_{C}=\frac{\theta}{F}=\frac{(0.535 / 0.840)}{0.983}=0.626$. It then means in the sense of the above-mentioned that the heat exchanger is over-dimensioned.

The values of the variables $\mathrm{NTU}_{1 C}$ and $\theta_{C}$, which in the sense of the equation (9) are the function of $P_{1}$ and $R_{1}$, can be quickly determined by means of figures 2 and 3 . These figures represent one of the possible ways how the type of functions $\mathrm{f}\left(P_{1}, R_{1}, \mathrm{NTU}_{1 C}\right)=0$ and $\mathrm{f}\left(P_{1}, R_{1}, \theta_{C}\right)=0$ can be displayed.

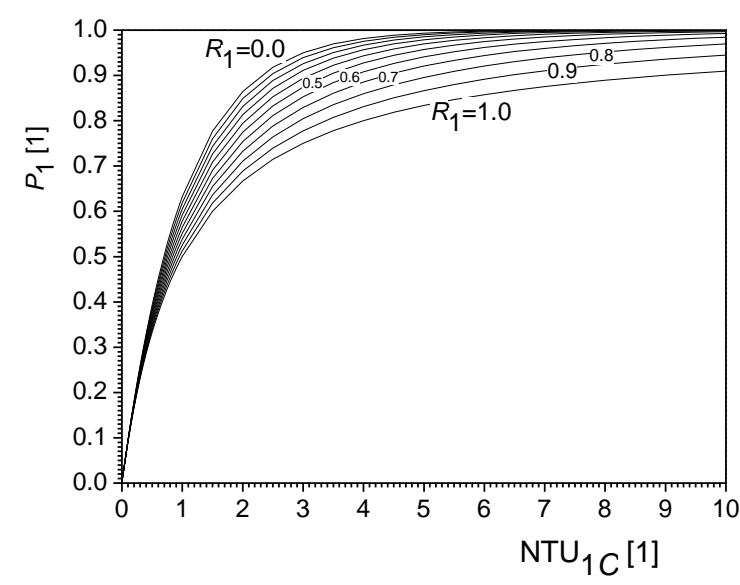

Fig. 2 The dependence of $P_{1}$ on $\mathrm{NTU}_{1 C}$ for a pure countercurrent heat exchanger, the curves parameter is $R_{1}$.

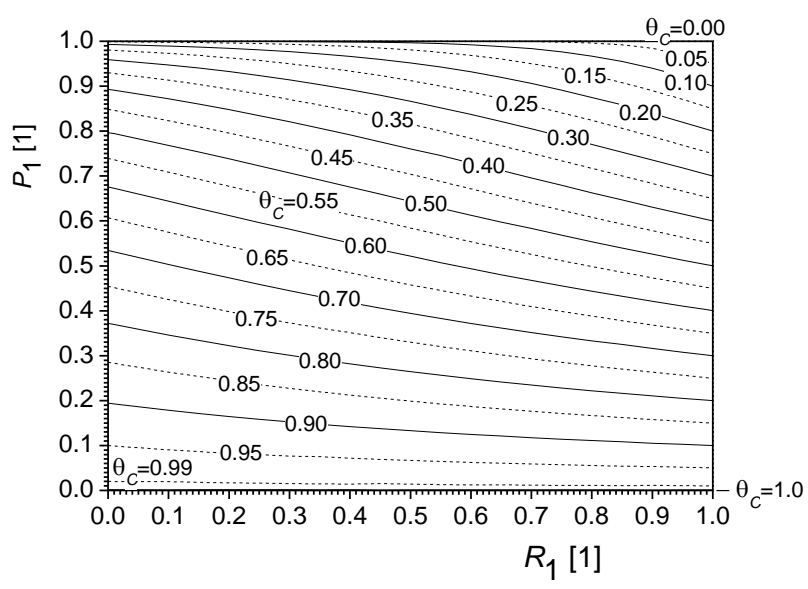

Fig. 3 The dependence of $P_{1}$ on $R_{1}$ for a pure countercurrent heat exchanger, the curves parameter is $\theta_{C}$.

The disadvantage of the equation (8) partially eliminates the following equation [14]:

$$
\mathrm{NTU}_{1}=\frac{1}{Z} \ln \left[\frac{2-\left(1+R_{1}-Z\right) P_{1}}{2-\left(1+R_{1}+Z\right) P_{1}}\right] \text {, where: } Z=\sqrt{\left(1+R_{1}\right)^{2}-4 p_{p} R_{1}} \text {, }
$$

in which the variable $p_{p}$ reflects a flow arrangement (the heat exchanger construction), in other words the heat exchanger type (for example: pure cocurrent flow $p_{p}=0$, pure countercurrent flow $p_{p}=1$, the 1-2 shell and tube heat exchanger with U-tubes $p_{p}=0.5$ and other variants in $[11,15]$. A certain disadvantage of this equation is ignorance of the variable $p_{p}$ for some types of the heat exchangers.

The uncertainty of the equation (11) against the verified experimentally data $P_{1}$ is not more than $2 \%$ if some recommendations for working with this equation are respected $[11,13]$. In connection with this equation it is mentioned that the mean value of the overall heat transfer coefficient $(\bar{k})$ can be determined with an accuracy better than $\pm 15.0 \%$ only in rare cases. For this reason the equation (11) is considered as the universal equation for determining the heat exchanger efficiency $\left(P_{1}\right)$. The analogical dependencies, such as those depicted in figures 2 and 3, can easily be created based on this equation. Figures 4 and 5 show the dependencies created by the equation (11). 


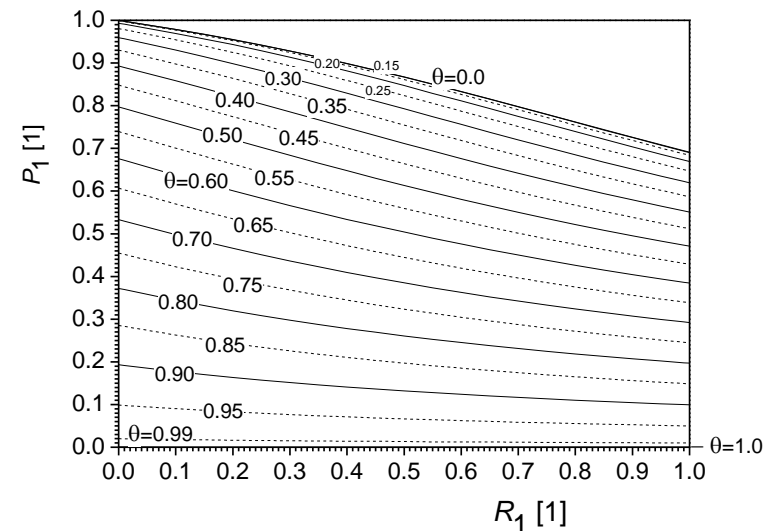

Fig. 4 The dependence of $P_{1}$ on $R_{1}$ for the heat exchanger with $p_{p}=0.8$, the curves parameter is $\theta$.

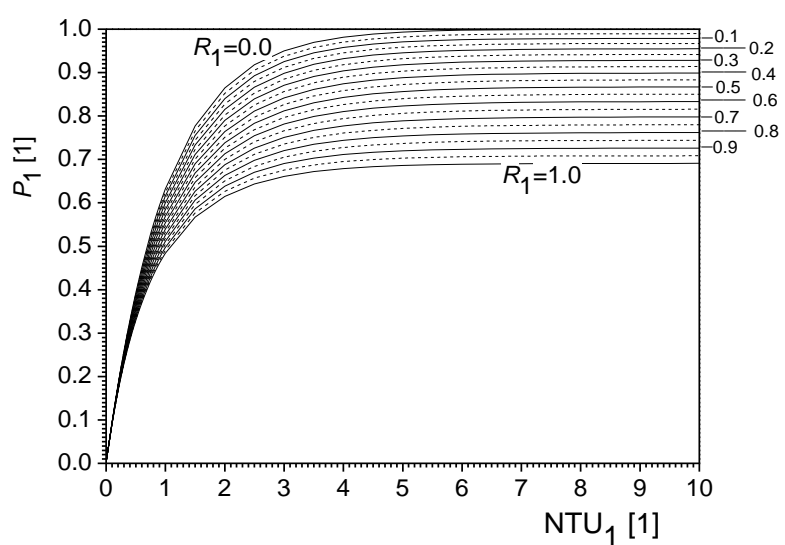

Fig. 5 The dependence of $P_{1}$ on NTU for the heat exchanger with $p_{p}=0.8$, the curves parameter is $R_{1}$.

\section{Facts resulting from the universal equations used to describe the heat exchangers}

There are cases when a heat exchanger with $p_{p} \neq 1.0$ needs to be used to solve a particular problem. In such cases it may happen that the task is not always solvable for the given input parameters. This known fact is illustrated in figures 4 and 5. The reason is that the key variable value cannot always be determined for specified input parameters. For example, when $P_{1}=R_{1}=0.9$ so $\theta$ or $\mathrm{NTU}_{1}$ cannot be determined for the heat exchanger with $p_{p}=0.8$. This confirms the figures 4 and 5 . The heat exchanger is not suitable for the given input parameters, therefore, another one must be used.

Another known fact is that not every type of the heat exchanger in terms of its operation is suitable for the given parameters. This fact is usually controlled by the variable $F$. If $F<0.75$, another type of the heat exchanger is recommended to select for the given conditions $[9,12]$. The solution may be considered as acceptable according to experience [16] when $F \in\langle 0.8 ; 1\rangle$. If the value $F$ is smaller than these recommended values, the most types of heat exchangers are sensitive and less stable against potential changes in the flow temperatures. This fact appears at the heat exchangers in which the flow arrangement is close to the flow arrangement of the pure cocurrent heat exchanger (in which $p_{p}=0.0$ ). The functional dependencies $F=\mathrm{f}\left(R_{1}, P_{1}\right)$ (figures 6 and 7) represent the stated fact well. These figures show that curves $F\left(R_{1}, P_{1}=\right.$ const. $)$ are vertical from a certain value of the variable $F$.

This causes the thermal instability of the streams because a small change of the value of the variable $R_{1}$ replies a large change of the variable $F$. For this reason, the heat exchanger should not work in areas where the slope of the curves is almost vertical.

In figures 6 and 7, some curves appear to be incomplete. The endings of these curves define the area of the applicability of the given heat exchanger. This fact is also commented at figures 4 and 5. It is customary, in terms of the commentary about the variable $F$, that the functional dependence of the type $F=\mathrm{f}\left(R_{1}, P_{1}\right)$ is presented only for values $F \geq 0.5$ (figures 8 and 9). 


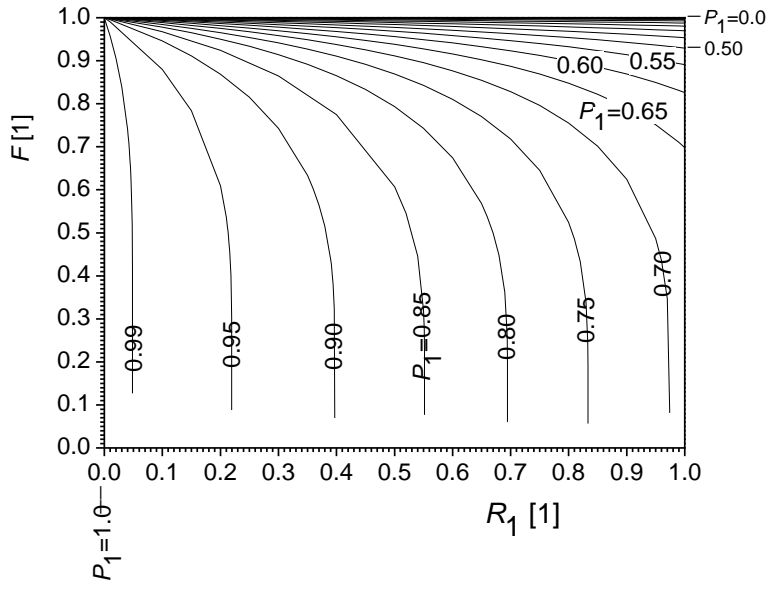

Fig. 6 The dependence of $F$ on $R_{1}$ for the heat exchanger with the countercurrent index $0.8\left(p_{p}=0.8\right)$, the curves parameter is $P_{1}$.

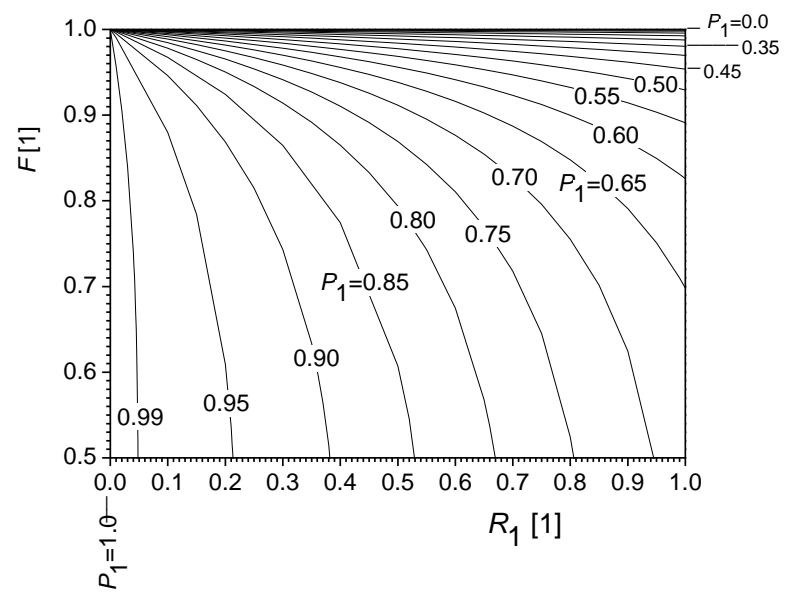

Fig. 8 The dependence of $F$ on $R_{1}$ for the heat exchanger with the countercurrent index $0.8\left(p_{p}=0.8\right)$, the curves parameter is $P_{1}$.

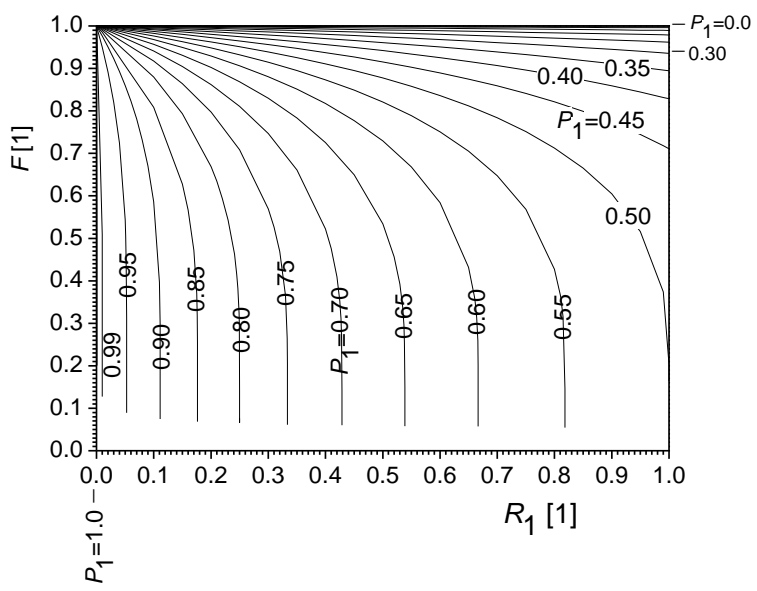

Fig. 7 The dependence of $F$ on $R_{1}$ for the heat exchanger with the countercurrent index $0.0\left(p_{p}=0.0\right)$, the curves parameter is $P_{1}$.

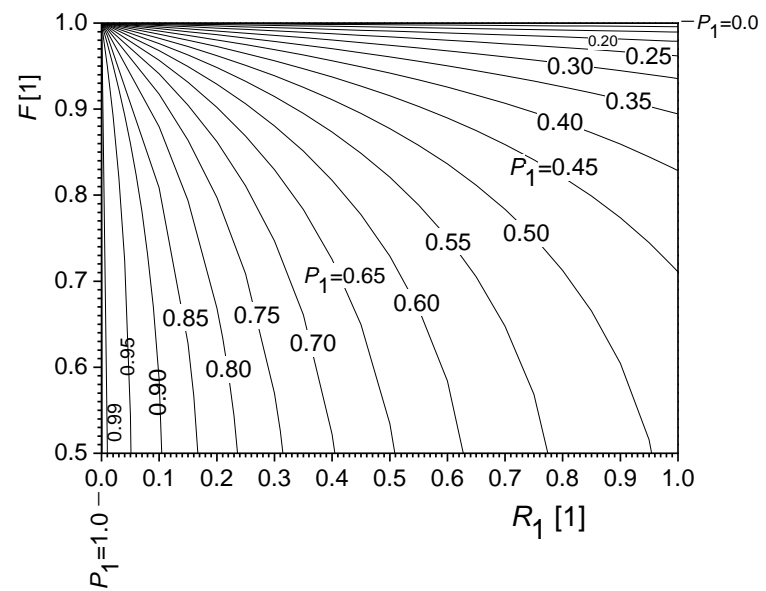

Fig. 9 The dependence of $F$ on $R_{1}$ for the heat exchanger with the countercurrent index $0.0\left(p_{p}=0.0\right)$, the curves parameter is $P_{1}$.

It is clear from the previous figures that the heat exchanger construction influences the value of the key variables. If the values of the key variables are determined for the specified input parameters (i.e. $P_{1}$ and $R_{1}$ ), these will differ for each type of the heat exchanger. Tab. 1 confirms just mentioned.

Tab. 1 The variables values $F, \theta$ and $\mathrm{NTU}_{1}$ for the different heat exchangers types, when: $P_{1}=R_{1}=0.5$.

\begin{tabular}{|l|c|c|c|c|c|}
\hline \multirow{2}{*}{$\begin{array}{l}\text { The key } \\
\text { variables }\end{array}$} & \multicolumn{5}{|c|}{ The heat exchanger with the countercurrent index } \\
\cline { 2 - 6 } & $p_{p}=0.0$ & $p_{p}=0.3$ & $p_{p}=0.5$ & $p_{p}=0.8$ & $p_{p}=1.0$ \\
\hline$F$ & 0.877 & 0.915 & 0.941 & 0.976 & 1.000 \\
\hline$\theta$ & 0.541 & 0.565 & 0.580 & 0.602 & 0.616 \\
\hline $\mathrm{NTU}_{1}$ & 0.924 & 0,885 & 0.861 & 0.830 & 0.810 \\
\hline
\end{tabular}


On the basis of the tab. 1 it can be stated that the key variables values belonging to the given heat exchanger lie within the value range defined by the values of the key variables belonging to the exchangers with $p_{p}=0.0$ and $p_{p}=1.0$. This is generally valid for any heat exchanger. This can be explained in such a way that each heat exchanger with $p_{p} \in(0.0 ; 1.0)$ can be imagined as the exchanger folded from the elements which represent the pure countercurrent and the pure cocurrent heat exchangers of the different sizes.

The case listed in table 1, including a comment to it, represents a design calculation of the heat exchanger. However, these conclusions also relate to the control calculation. This is characterised by the fact that known values are for example $\mathrm{NTU}_{1}$ and $F$, unknown is $P_{1}$. This is documented in tab. 2. Based on this table, it can also be stated that the value of the variable $P_{1}$ is also always from the value range defined by the values of this variable belonging to the exchangers with $p_{p}=0.0$ and $p_{p}=1.0$.

Tab. 2 The values $P_{1}$ for the different heat exchangers types, when: $R_{1}=0.5$ and $\mathrm{NTU}_{1}$.

\begin{tabular}{|l|c|c|c|c|c|}
\hline \multirow{2}{*}{$P_{1}$} & \multicolumn{5}{|c|}{ The heat exchanger with the countercurrent index } \\
\cline { 2 - 6 } $\mathrm{NTU}_{1}$ & $p_{p}=0.0$ & $p_{p}=0.3$ & $p_{p}=0.5$ & $p_{p}=0.8$ & $p_{p}=1.0$ \\
\hline 0.5 & 0.352 & 0.355 & 0.357 & 0.360 & 0.362 \\
\hline 2.5 & 0.651 & 0.691 & 0.724 & 0.783 & 0.833 \\
\hline 5.5 & 0.666 & 0.718 & 0.763 & 0.860 & 0.967 \\
\hline
\end{tabular}

\section{Definition of the limit values of the key variables and the heat exchanger efficiency}

The previous part of the paper documents that the variables values $\mathrm{NTU}_{1}, F, \theta$ and $P_{1}$ for the heat exchanger with $p_{p} \in(0.0 ; 1.0)$ are always from the range value of the key variables belonging to the exchangers with $p_{p}=0.0$ and $p_{p}=1.0$. The following analytical relationships can be used for determining the value range, alternatively limit values, of $\mathrm{NTU}_{1}$ and $P_{1}$ :

$$
\begin{gathered}
\frac{\mathrm{NTU}_{1 C}}{\mathrm{NTU}_{1 C O}}=F=\frac{\left(1+R_{1}\right) \ln \left(\frac{1-R_{1} P_{1}}{1-P_{1}}\right)}{-\ln \left[1-P_{1}\left(1+R_{1}\right)\right]\left(1-R_{1}\right)}, \\
\frac{P_{1 C O}}{P_{1 C}}=\frac{\left[1-\mathrm{e}^{-\mathrm{NTU}_{1}\left(R_{1}+1\right)}\right]\left[1-R_{1} \mathrm{e}^{\left(R_{1}-1\right) \mathrm{NTU}_{1}}\right]}{\left[1-\mathrm{e}^{\left(R_{1}-1\right) \mathrm{NTU}_{1}}\right]\left(1+R_{1}\right)}
\end{gathered}
$$

The equations (12) and (13) are derived from the equations describing the behaviour of the pure countercurrent and the pure cocurrent heat exchanger. Figures 10 and 11 represent a graphical interpretation of these equations. If the limit values of the variables $\mathrm{NTU}_{1}$ and $P_{1}$ are to be defined by the values $\mathrm{NTU}_{1 C} / \mathrm{NTU}_{1 C O}$ and $P_{1 C O} / P_{1 C}$, the variables values must be subsequently calculated in accordance with the equation (9). The limit values of other key variables (i.e. $F$, alternatively $\theta$ ) can then be obtained by the equation (10). 
For example, in the case of a design calculation, when $P_{1}=R_{1}=0.5$, then $\mathrm{NTU}_{1 C}=0.810$ and $\frac{\mathrm{NTU}_{1 C}}{\mathrm{NTU}_{1 C O}}=0.877=F$. It then means that the values of the relevant key variables for a given heat exchanger must be from the following values ranges: $\mathrm{NTU}_{1} \in$ $\in\left\langle\mathrm{NTU}_{1 C} ; \mathrm{NTU}_{1 C O}\right\rangle=\langle 0.810 ; 0.924\rangle, \quad \theta \in\left\langle\theta_{C O} ; \theta_{C}\right\rangle=\langle 0.541,0.616\rangle \quad$ and $\quad F \in\left\langle F_{C O} ; F_{C}\right\rangle=$ $=\langle 0.877 ; 1.000\rangle$. In the case of a control calculation, when $\mathrm{NTU}_{1}=0.840$ and $R_{1}=0.111$, then in accordance with the equation (13) $\frac{P_{1 C O}}{P_{1 C}}=0.983$. It means that $P_{1} \in\left\langle P_{1 C O} ; P_{1 C}\right\rangle=$ $=\langle 0.546 ; 0.555\rangle$ because in accordance with the equation (9): $P_{1 C}=0.555$.

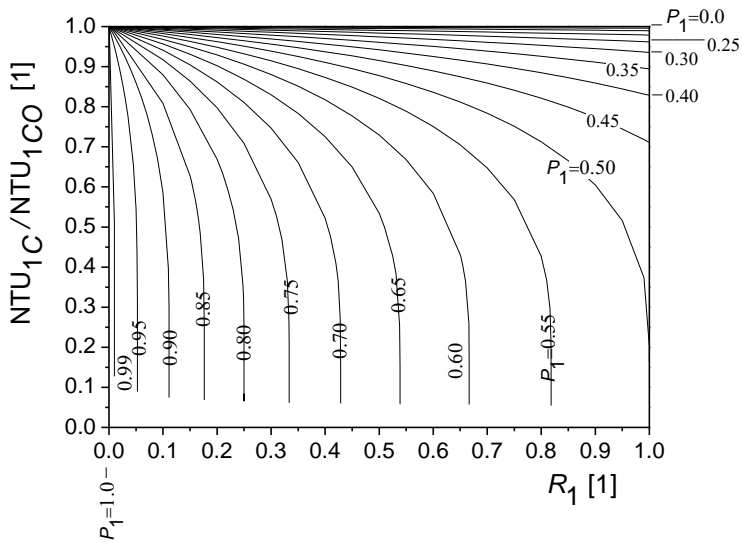

Fig. 10 The dependence of $\frac{\mathrm{NTU}_{1 C}}{\mathrm{NTU}_{1 C O}}$ on $R_{1}$ for any heat exchanger, the curves parameter is $P_{1}$.

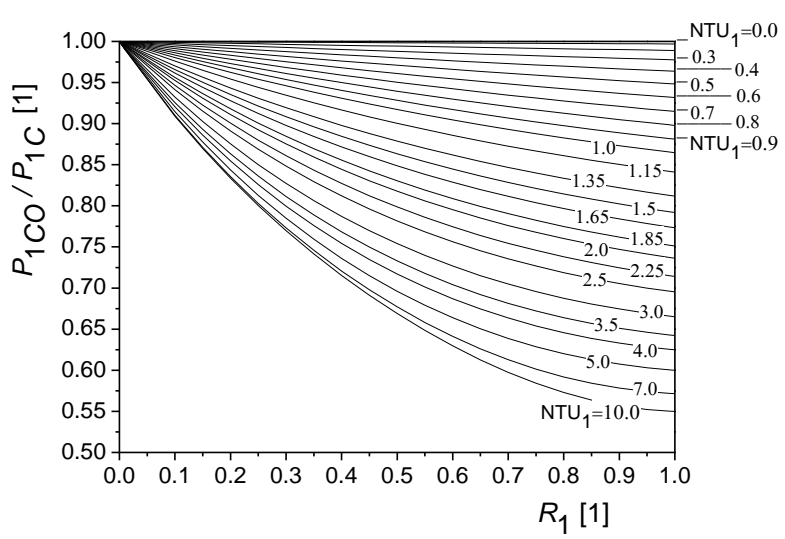

Fig. 11 The dependence of $\frac{P_{1 C O}}{P_{1 C}}$ on $R_{1}$ for any heat exchanger, the curves parameter is $\mathrm{NTU}_{1}$.

Based on the figures 10 and 11 , the following generally valid fact, regarding the heat exchanger construction, can be noted. If values of the ratios $\mathrm{NTU}_{1 C} / \mathrm{NTU}_{1 C O}$ and $P_{1 C O} / P_{1 C}$ approximate to 1, the heat exchanger construction (the stream arrangement of heat exchange fluids) does not play a significant role in terms of the heat transfer. It then means that the heat exchanger calculation can be done by the heat transfer rate equation valid for the pure countercurrent heat exchanger. This fact illustrates well figure 12, which shows the same dependence as figure 4. Figure 12 shows the dependencies for the heat exchangers with $p_{p}=0.0$ (the dashed lines) and $p_{p}=1.0$ (the full lines). This figure shows the curves $P_{1}\left(R_{1}, \theta=\right.$ const. $)$, which always start from one point, represent the given heat exchangers. The curves represent all other exchangers, in which $p_{p} \in(0.0 ; 1.0)$, lie between these two curves and also start from one point. This situation is well illustrated in figure 13. These figures document another known fact. For the same input parameters, the highest heat exchanger efficiency $\left(P_{1}\right)$ is always obtained in the pure countercurrent heat exchanger $\left(p_{p}=1.0\right)$ and the lowest in the pure cocurrent heat exchanger $\left(p_{p}=0.0\right)$.

The cases when $F=1.0$ for any heat exchanger can be identified by figure 12 . The points that overlap each other represent these cases. The knowledge of this may sometimes be advantageously used if some freedom exists in the heat exchanger calculation. Under the freedom is thought that one of the values (for example temperature, heat capacity) can be 
chosen so that $F$ equals 1 in the calculation. Subsequently, the calculation of the heat exchanger will happen easy.

For example, if $R_{1}=0$ (alternatively approaching to zero) in the calculation, for the various types of the heat exchangers $F$ is always equal to 1 for any values of $P_{1}$ (figure 12). In the sense just mentioned, the following equation can be written:

$$
P_{1}=1-\mathrm{e}^{-F \mathrm{NU}_{1}}=1-\mathrm{e}^{-\mathrm{NTU}_{1}} \text {, or: } \mathrm{NTU}_{1}=\frac{1}{F} \ln \left(\frac{1}{1-P_{1}}\right)=-\ln \left(1-P_{1}\right) .
$$

This equation is valid for any flow arrangements if $R_{1}=0$ or when $R_{1}$ approaching to zero (i.e. $R_{1} \rightarrow 0$ ). In this special case, $F=1$ in the equation (14), which confirms also the equations (12) and (13). If $R_{1}=0$ in these equations, the expressions $\frac{\mathrm{NTU}_{1 C}}{\mathrm{NTU}_{1 C O}}=F$ and $P_{1 C O} / P_{1 C}$ also equal 1 (i.e. $\mathrm{NTU}_{1 C} / \mathrm{NTU}_{1 C O}=F=1$ and $P_{1 C O} / P_{1 C}=1$ ).

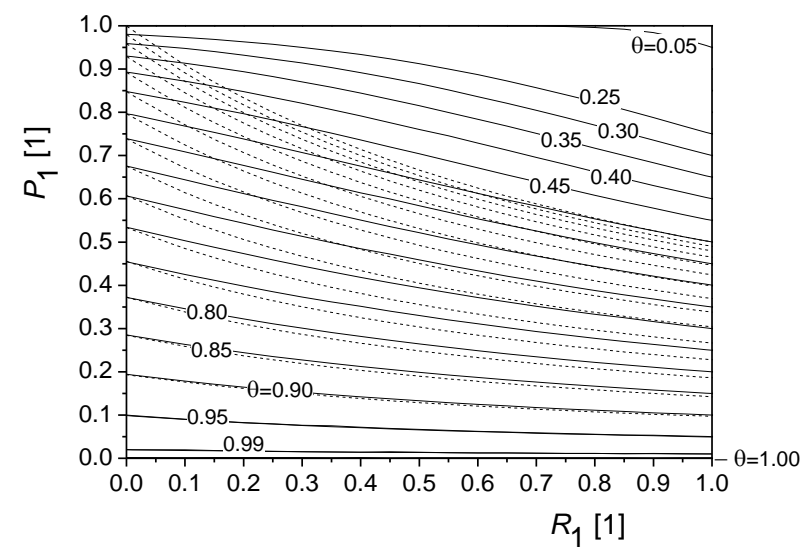

Fig. 12 The dependence of $P_{1}$ on $R_{1}$ for the heat exchanger with $p_{p}=1.0$ (the full lines) and $p_{p}=0.0$ (the dashed lines), the curves parameter is $\theta$.

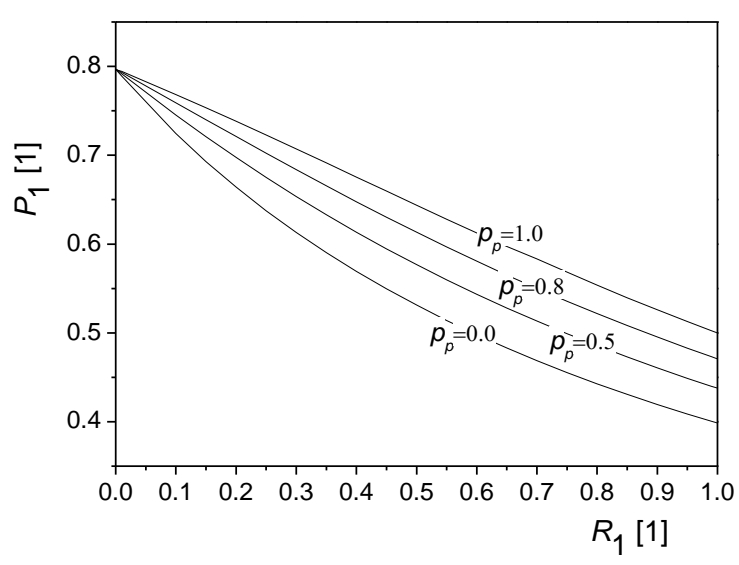

Fig. 13 The dependence of $P_{1}$ on $R_{1}$ for $\theta=0.50$, the curves parameter is $p_{p}$.

Based on the above, it is now possible to return to the values from the article introduction for which it was found that $F=0.983$ and $\mathrm{NTU}_{1}=0.840$. If the values $P_{1}=0.535$ and $R_{1}=0.111$ are put into equations (9) and (12) then $\mathrm{NTU}_{1 C}=0.792$ and $\mathrm{NTU}_{1 C} / \mathrm{NTU}_{1 C O}=0.976$. It means: $\mathrm{NTU}_{1} \in\langle 0.792 ; 0.857\rangle$ and in the sense of the equation (10), it is also possible to write: $\theta \in\langle 0,624,0.676\rangle$ and $F \in\langle 0.976 ; 1.000\rangle$. From these values it follows that the values $F=0.983$ and $\mathrm{NTU}_{1}=0.840$ are within the values ranges of the key variables. However, these values do not suit the generally valid equations, the equation (8) and the equation (10). It can be stated that the heat exchanger is over-dimensioned (because the value $\mathrm{NTU}_{1 C}=0.792$ is not obtained from the equation (10)) and the heat exchanger is not designed in accordance with generally applicable principles (because the value $P_{1}=0.535$ is not obtained from the equation (8)).

If the heat exchanger is over-dimensioned, one of the streams can be cooled to a lower temperature than required and the second stream is heated to a higher temperature than required. In the case of the under-dimensioned heat exchanger, it is on the contrary. None of 
the streams can reach the desired outlet temperature if the heat exchanger is underdimensioned. It is necessary to realise that the variables $P_{1}$ and $P_{2}$, in the sense of equations (4) and (5), are bound by the relation:

$$
P_{h} / P_{c}=R_{c}=1 / R_{h}=\left(T_{h}^{\prime}-T_{h}^{\prime \prime}\right) /\left(T_{c}^{\prime \prime}-T_{c}^{\prime}\right) .
$$

The interconnection of these variables is reflected in the values of the outlet streams temperatures as it follows from the equation (4). According to this equation, it can be written:

$$
T_{h}^{\prime \prime}=T_{h}^{\prime}-P_{h}\left(T_{h}^{\prime}-T_{c}^{\prime}\right) \text { a } T_{c}^{\prime \prime}=T_{c}^{\prime}+P_{c}\left(T_{h}^{\prime}-T_{c}^{\prime}\right) .
$$

The table 3, tjat is the last one listed in the article, allows to analyse an effect of the value $\mathrm{NTU}_{1}$ on the thermal efficiency of the heat exchanger. The minimum value of the number of transfer units $\left(\mathrm{NTU}_{1}\right)$, when $R_{1}=0.111$, should be 0.812 if the desired thermal efficiency value is to be definitely achieved (i.e. $P_{1}=0.535$ ) for any flow arrangement. This follows from the last table (Table 3). Such consideration may be used provided that the function (6) is not available for the heat exchanger. The results of such consideration is that $P_{1}$ will always be greater than 0.535 or equal to 0.535 (i.e. $P_{1} \geq 0.535$ ) for any heat exchanger. In other words, each exchanger can be operated in order to achieve a value $P_{1}=0.535$.

Otherwise, if the certain value $P_{1}$ is not to be exceeded at designing a heat exchanger with $p_{p} \in(0.0 ; 1.0)$, the same procedure can be used. In this case, the output temperatures cannot also be exactly determined, because the function (6) is unknown. Again, the temperatures ranges in which the output temperatures will move can be defined.

Tab. 3 The values $P_{1}$ for the different heat exchangers types, when: $R_{1}=0.111$ and $\mathrm{NTU}_{1}$ is variable.

\begin{tabular}{|l|c|c|c|c|c|}
\hline \multirow{2}{*}{$P_{1}$} & \multicolumn{5}{|c|}{ The countercurrent index of the heat exchanger } \\
\cline { 2 - 6 } $\mathrm{NTU}_{1}$ & $p_{p}=0.0$ & $p_{p}=0.3$ & $p_{p}=0.5$ & $p_{p}=0.8$ & $p_{p}=1.0$ \\
\hline 0.792 & 0.527 & 0.529 & 0.531 & 0.533 & 0.535 \\
\hline 0.802 & 0.531 & 0.533 & 0.535 & 0.537 & 0.539 \\
\hline 0.812 & 0.535 & 0.537 & 0.539 & 0.542 & 0.543 \\
\hline 0.840 & 0.546 & 0.549 & 0.551 & 0.553 & 0.555 \\
\hline 0.857 & 0.553 & 0.556 & 0.557 & 0.560 & 0.562 \\
\hline
\end{tabular}

\section{Conclusion}

The article summarises the basic variables and the functional dependences used in the description of the heat exchangers. The dependence $P_{1}=\mathrm{f}\left(\mathrm{NTU}_{1}, R_{1}\right)$ can be considered as the most practical. This dependence allows to carry out not only design but also control calculation of a heat exchanger very easily. The article also points to the importance of the variable $F$ which is used for the assessment of the suitability of the heat exchanger. For this reason, the graphical dependencies should always allow to deduct both variables, i.e. $F$ and $\mathrm{NTU}_{1}$, ideally from one diagram. This allows, for example, Method Roetzel-Spang [17].

Further, the article deals with the determination of the limit values of the key variables and variable $P_{1}$, for given input parameters, between which should fall the values of these variables. The limit values are determined on the basis of generally valid equations which pertain to the heat exchanger with $p_{p}=0.0$ and $p_{p}=1.0$. The reason for this is fact that the 
values of these variables (i.e. $F, \theta, \mathrm{NTU}_{1}$ and $P_{1}$ ) for any heat exchanger (i.e. $\left.p_{p} \in(0.0 ; 1.0)\right)$ always lie between the values corresponding to the pure countercurrent and the pure cocurrent heat exchanger. The limit values define the values ranges of the variables $F, \theta, \mathrm{NTU}_{1}$ and $P_{1}$. These values ranges allow to assess whether the values of these variables, belonging to any heat exchanger for the given input parameters, are real.

Finally, the article discusses the fact that $F \cong 1.0$ for a certain combination of the variables values and some heat exchanger. The article also points out how to estimate the values of the keys variables when a function (6) is not available for a heat exchanger with $p_{p} \in(0.0 ; 1.0)$. However, it should be kept in mind that such a procedure may lead to over-dimensioning or under-dimensioning of the heat exchanger.

The knowledge of the key variables values is a necessary basis for performing an adequate thermal calculation of any heat exchanger resulting in the knowledge the size of the heat transfer area. It should be noted that the calculation of any equipment is complete only when a hydraulic and also economical calculation of given equipment is made. Only then it can be stated which value of the heat transfer area size is the most advantageous.

\section{Acknowledgements}

This contribution was created on the basis of the project "Research centre ALLEGRO" (ITMS project code: 26220220198) supported by Operational Programme Research and Development funded by the European Regional Development Fund.

\section{Nomenclature}

\section{Latin Letters}

\begin{tabular}{|c|c|c|c|}
\hline$A$ & heat transfer area $\left[\mathrm{m}^{2}\right]$ & & difference $[\mathrm{K}]$ \\
\hline$C_{p}$ & heat capacity flow rate at constant & $\dot{m}$ & mass flow rate $[\mathrm{kg} / \mathrm{s}]$ \\
\hline$c_{p}$ & $\begin{array}{l}\text { pressure }[\mathrm{W} / \mathrm{K}] \\
\text { specific heat capacity at constant } \\
\text { pressure }[\mathrm{J} /(\mathrm{kgK})]\end{array}$ & $\begin{array}{l}\text { NTU } \\
P\end{array}$ & $\begin{array}{l}\text { number of transfer units [1] } \\
\text { dimensionless temperature } \\
\text { change [1] }\end{array}$ \\
\hline$F$ & logarithmic mean temperature & $p_{p}$ & countercurrent index [1] \\
\hline$k$ & $\begin{array}{l}\text { difference correction factor }[1] \\
\text { overall heat transfer coefficient } \\
{\left[\mathrm{W} /\left(\mathrm{m}^{2} \mathrm{~K}\right)\right]}\end{array}$ & $\begin{array}{l}R \\
T \\
\dot{Q}\end{array}$ & $\begin{array}{l}\text { heat capacity rate ratio }[1] \\
\text { temperature }[\mathrm{K}] \\
\text { heat flow rate }[\mathrm{W}]\end{array}$ \\
\hline LMTD & logarithmic mean temperature & $Z$ & auxiliary parameter [1] \\
\hline \multicolumn{4}{|c|}{ Greek Letters } \\
\hline$\overline{\Delta T}$ & mean temperature difference $[\mathrm{K}]$ & $\Phi$ & heat exchanger efficiency [1] \\
\hline$\Delta T_{l n}$ & $\begin{array}{l}\text { logarithmic mean temperature } \\
\text { difference }[\mathrm{K}]\end{array}$ & $\theta$ & $\begin{array}{l}\text { dimensionless mean } \\
\text { temperature difference [1] }\end{array}$ \\
\hline \multicolumn{4}{|c|}{ Subscripts } \\
\hline$c$ & cold medium & $\max$ & stronger stream, maximum \\
\hline$C$ & pure countercurrent flow & 1 & weak stream \\
\hline $\begin{array}{l}C O \\
h\end{array}$ & $\begin{array}{l}\text { pure cocurrent flow } \\
\text { hot medium }\end{array}$ & $\underline{2}$ & $\begin{array}{l}\text { stronger stream } \\
\text { mean value }\end{array}$ \\
\hline $\begin{array}{l}i \\
\min \end{array}$ & $\begin{array}{l}\text { ith medium } \\
\text { weak stream, minimum }\end{array}$ & ' & $\begin{array}{l}\text { at the inlet } \\
\text { at the outlet }\end{array}$ \\
\hline
\end{tabular}




\section{REFERENCES}

[1] F. Dzianik, Š. Gužela, E. Puškášová. Thermal Characteristics of High Temperature Naturally Circulating Helium Cooling Loop. Journal of Mechanical Engineering Strojnicky časopis 2018 (68), No. 1, 5 - 14. DOI: 10.2478/scjme-2018-0001

[2] Š. Gužela, F. Dzianik, M. Juriga, J. Kabát. Shell and Tube Heat Exchanger - the Heat Transfer Area Design Process. Journal of Mechanical Engineering - Strojnícky časopis 2017 (67), No. 2, 13 - 24. DOI: 10.1515/scjme-2017-0014

[3] K. Punitharani, V. Parameshwaran. Effect of Exhaust Gas Recirculation on Performance of a Diesel Engine Fueled with Waste Plastic Oil / Diesel Blends. Journal of Mechanical Engineering - Strojnícky časopis 2017 (67), No. 2, 91 - 100. DOI: $10.1515 /$ scjme-2017-0022

[4] F. Dzianik, Š. Gužela. Hydrodynamic Properties of High Temperature Natural Circulating Helium Cooling Loop. Journal of Mechanical Engineering - Strojnicky časopis 2017 (67), No. 1, 29 - 36. DOI: 10.1515/scjme-2017-0003

[5] N. Kapilan, M. Manjunath Gowda, H. N. Manjunath. Computational Fluid Dynamics Analysis of an Evaporative Cooling System. Journal of Mechanical Engineering Strojnicky časopis 2016 (66), No. 2, 117 - 124. DOI: 10.1515/scjme-2016-0026

[6] R. A. Bowman, A. C. Mueller. Nagle.: Mean temperature difference in design. 62, ASME Transaction, 1940.

[7] W. M. Kays, London A. L.: Compact heat exchangers, 2nd ed. New York : McGrawHill Book Co., 1964.

[8] A. C. Mueller, W. M. Rohsenow, J. P. Hartlett. Handbook of heat transfer, Sec. 18, Heat exchangers, $1-113$. New York: McGraw-Hill, 1973.

[9] K. Jelemenský, J. Šesták, R. Žitný. Tepelné pochody, 2. vydanie. Bratislava: Vydavatel'stvo STU v Bratislave, 2004.

[10] VDI Heat Atlas, Second Edition, Springer-Verlag Berlin Heidelberg, 2010, ISBN 9783-540-77876-9.

[11] V. Hlavačka. Termická účinnost výměníků tepla, Technické př́ručky 1, PraheBěchovice : SVÚSS, 1988.

[12] E.Cao: Heat Transfer in process Engineering, ISBN: 978-0-07-162613-2, The McGrawHill, 2010.

[13] K. Ferstl, M. Masaryk. Prenos tepla, 1. vydanie, ISBN 978-80-227-3534-6, STU v Bratislave, 2011.

[14] J. Schneller, V. Hlavačka. Význam termickej účinnosti při výpočtech jednoduchých i složitějších teplosměnných systémů, Strojírenství 61972 (22).

[15] Hlavačka V. Standardní postupy pro výpočet výměníku tepla, Praha, MAPRINT, 1995.

[16] E. Slavíček. Potravinářské inženýrství II. Praha : SNTL, 1958.

[17] W. Roetzel, B. Spang. Vefbessertes Giagramm zur Berechnung von Wänneüberttragern. Wärme-unf Stoffübertragung 1990 (25), 259 - 264. 